\title{
FUEL AND ASH PROPERTIES OF BIOCHAR PRODUCED FROM MICROWAVE-ASSISTED CARBONISATION OF OIL PALM TRUNK CORE
}

\author{
HANISOM ABDULLAH*; WUN SHUN JIE*; NORJAN YUSOF* and ILLYAS MD ISA**
}

\begin{abstract}
Oil palm trunk core (OPTC) is the biomass left over from plywood industry that utilises oil palm trunk as feedstock. This research aims to investigate the fuel and ash properties of biochar converted from OPTC biomass through microwave-assisted carbonisation process. The raw OPTC contains high moisture ( $64.3 \%)$ with low fixed carbon ( 6.4\%) and calorific value (4.6 $\left.\mathrm{MJ} \mathrm{kg}^{-1}\right)$. Microwave-assisted carbonisation of OPTC was investigated under several sizes, temperature and microwave power variables. The results showed that biochar yield decreased with the increasing carbonisation temperature. The optimum conditions yielding $8.4 \%$ biochar was obtained at $350^{\circ} \mathrm{C}$, microwave power $800 \mathrm{~W}$ and $6 \mathrm{~cm}$ cube. Compared to raw OPTC, biochar has higher fixed carbon ( 20-64\%) and about four times higher calorific value than the raw OPTC. In general, all of the biochars produced in this study showed higher alkali index and total alkali values than those obtained from raw OPTC. Feedstock size seemed to affect biochar ash properties in this study. Biochar obtained from $6 \mathrm{~cm}$ cube tend to have lower slagging and fouling tendency than those produced with $4 \mathrm{~cm}$ cube.
\end{abstract}

Keywords: biomass, biochar, ash, alkali, slag.

Date received: 12 April 2015; Sent for revision: 17 June 2015; Received in final form: 28 November 2015; Accepted: 13 January 2016.

\section{INTRODUCTION}

In Malaysia, the annual availability of felled oil palm trunks (OPT) was estimated to be $\sim 15$ million tonnes (Eom et al., 2015). At present, a small portion of the OPT biomass is utilised in the timber industry. Around $40 \%$ of OPT biomass is consumed in the production of particleboard, mineral bonded particleboard, block board, cement board, medium density fibreboards, fibre-reinforced cement boards,

\footnotetext{
* Biology Department, Faculty of Science and Mathematics, Universiti Pendidikan Sultan Idris, 35900 Tanjung Malim, Perak, Malaysia. E-mail: hanisom@fsmt.upsi.edu.my

** Chemistry Department, Faculty of Scince and Mathematics, Universiti Pendidikan Sultan Idris, 3900 Tanjung Malim, Perak, Malaysia.
}

fibre-plastic composites, plywoods, blockboards, laminated-veneer lumbers and furniture (Wan Asma et al., 2010; Loh et al., 2011; Dungani et al., 2013; Lee et al., 2015). Of a whole OPT biomass, the consumption of the centre of OPT is limited by its morphology and weak mechanical performance because oil palm is monocotyledon without secondary thickening (Szymona et al., 2011). Hence, oil palm trunk core (OPTC) is normally left out as waste in timber industry. In bioenergy applications, raw biomass can be used directly as boiler fuels but the consumption is rather limited to around 5\%-10\% because the process suffers from inefficient energy conversion and high fuel production cost due to biomass property mismatched to those of coal (Trummer, 2004; Abdullah and $\mathrm{Wu}, 2009)$. Raw biomass is bulky, high in moisture, low in volumetric energy 
density, and low in terms of grindability due to its fibrous nature (Abdullah and $\mathrm{Wu}, 2009$ ). Therefore, it is imperative to convert raw OPTC into biofuels with enhanced properties for various applications in the future.

In this study, microwave-assisted carbonisation was carried out to convert OPTC into biochar. Carbonisation is one of the thermochemical conversion methods used to increase the efficiency of energy conversion. The method is used to produce charcoal by heating the biomass in an almost or complete absence of air or oxygen (Yokoyama and Matsumura, 2008). Compared to conventional heating, microwave heating is able to perform carbonisation of biomass with numerous advantages including material selective, and offering non-contact, rapid heating of large volume of biomass. Under microwave irradiation, the biomass molecules absorb the electromagnetic energy and store it as potential energy. Kinetic energy is then produced as polar molecules in biomass vibrate by the mechanism of ionic conduction and dipole rotation. Consequently, the kinetic energy causes friction between these molecules leading to heating with heat transfer direction coming out from the centre of biomass material towards its surface. In addition, microwave heating is easy to control: it can be operated and terminated quickly, and the safety and automation of the heating is high (Haque, 1999; Menéndez et al., 2002; 2005; 2010; Robinson et al., 2010). One of the most fundamental properties of microwave energy application in the thermal degradation of biomass is being material-selective heating, which results in different microwave energy absorption for different biomass or biomass dielectric properties (Menéndez et al., 2010; Omar et al., 2010). The application of microwave in thermochemical conversion became the focus of the present study because recent developments in microwave pyrolysis have achieved interesting and valuable results (Zhao et al., 2010; Miura et al., 2004; Amouzgar et al., 2010).

Slow pyrolysis is also often referred to as carbonisation. There are new technologies such as fixed bed, fluidised bed, bubbling fluidised bed, circulating fluidised bed, ablative and vortex reactor applied in the design of pyrolysis reactors to increase the yield product of carbonisation (Jahirul et al., 2012). However, these reactors are only suitable for granular materials and not for application on logged biomass. In the past 100 years, studies on the pyrolysis of largesized biomass were scarce (Pelaez-Samaniego et al., 2008). In this study, biomass is applied in block unit rather than ground form. Besides that, microwaveassisted carbonisation of OPTC was performed at low temperature $\left(300^{\circ} \mathrm{C}-400^{\circ} \mathrm{C}\right)$. This is because a previous study which used conventional heat source at $300^{\circ} \mathrm{C}$ to $400^{\circ} \mathrm{C}$ to perform slow pyrolysis on Australian woody biomass, produced biochar with improved grindability and fuel properties that highly matched to those of Collie coal's (Abdullah and $\mathrm{Wu}, 2009$ ). In the Malaysian context of biochar production from OPTC biomass, the carbonisation of OPTC and its biochar fuel and ash properties has not been fully investigated, particularly the process within the low range of pyrolysis temperatures. This article reports the fuel and ash properties of biochars obtained from microwave-assisted carbonisation of OPTC. With the advantages of microwave heating, the interest of the present study is on the systematic examination of the carbonisation of OPTC biomass that are controlled by such low carbonisation temperatures, particularly by using microwave as heat source. Any improvement in OPTC biochar fuel properties will significantly be advantageous for energy densification, increasing combustion efficiency and enhancing fuel processing/handling. All these, in turn, will open more opportunities for generating high quality biofuels from oil palm biomass. This will help to secure the Malaysian bioenergy production in the near future.

\section{MATERIALS AND METHODS}

\section{Biomass}

OPTC was collected from Plus Intervest Sendirian Berhad which is an oil palm plywood factory at Batu Kikir, Negeri Sembilan, Malaysia. The OPTC waste was collected after the peeling process in plywood production at the factory. The OPTC was received in cylinder log around $20 \mathrm{~cm}$ length and $8 \mathrm{~cm}$ in diameter. The feedstock was stored at $-20^{\circ} \mathrm{C}$ to avoid microbial degradation. For microwave pyrolysis, OPTC log was cut to $11 \times 15$ $\mathrm{cm}$ (diameter $x$ length) to be fitted in the microwave oven cavity.

For the carbonisation experiment, the OPTC was cut into cubes of two dimensions, $4 \times 4 \times 4 \mathrm{~cm}$ and 6 $x 6 \times 6 \mathrm{~cm}$ (length $\mathrm{x}$ width $\mathrm{x}$ height) weighing $\sim 67 \mathrm{~g}$ and $\sim 190$ g, respectively in order to study the effects of different OPTC sizes. Then, a hole $(2 \mathrm{~cm}$ in depth and $0.9 \mathrm{~cm}$ in diameter) was made at the centre of the OPTC cubes for inserting the thermocouple. This was to measure the inner temperature of sample during carbonisation.

\section{Carbonisation Experiment}

The carbonisation experiment was carried out by using a microwave reactor. The 20-litre microwave reactor system was designed in-house by using a domestic microwave with a frequency of $2.45 \mathrm{GHz}$. A thermocouple was used to measure the sample temperature in the microwave chamber 
during carbonisation. Teflon tape was used to cover the steel connector at the joint of thermocouple rod which was exposed into reactor cavity in order to reduce occurrence of sparkling resulting from interaction of thermocouple's reflective surface and electromagnetic wave. The temperature reading was shown on the digital temperature reading screen. The set-up rig of the microwave reactor is shown in Figure 1.

For the carbonisation experiment, the OPTC biomass was placed in the microwave chamber at room temperature. A thermocouple was inserted in the sample bed for temperature measuring and control. Nitrogen of $99.99 \%$ purity was used as carrier gas at a flow rate of 15 litres $\mathrm{min}^{-1}$. The nitrogen was allowed to flow through the reactor for 5 min to create an inert environment before starting the carbonisation process. The carbonisation of the OPTC biomass was carried out with OPTC cubes of $4 \mathrm{~cm}$ and $6 \mathrm{~cm}$, respectively. The OPTC was used as received without drying (64\% moisture) because based on a previous study the inherent moisture bound in OPTC was found to assist microwave energy absorption into the biomass (Wun et al., 2015). The OPTC of each size was carbonised under temperatures of $300^{\circ} \mathrm{C}$ to $400^{\circ} \mathrm{C}$ and microwave power in a range of $450 \mathrm{~W}$ to $800 \mathrm{~W}$. The desired temperature was held for $15 \mathrm{~min}$. Due to selective heating nature of microwave, heat rate was not controlled in the rig set up. After each experiment, the biochar sample was cooled down with nitrogen flow. The excessive nitrogen gas was allowed to flow to the suction system and released to the atmosphere. After the cooling process, the biochar was collected and stored in a desiccator before weighing. The carbonisation experiment was repeated twice. The biochar yield was calculated according to Equation (1) for different sizes, temperatures and microwave power.
Biochar yield $(\%)=\frac{\text { mass of residue after carbonisition }(\mathrm{g})}{\text { mass of initial OPTC }(\mathrm{g})} \times 100 \%$

Equation (1)

\section{Analysis of OPTC and Biochar}

OPTC and biochar were analysed in terms of their fuel and ash properties. OPTC and biochar were ground to particle size $<1 \mathrm{~mm}$ and representative samples were taken using quartering method for analyses. A proximate analysis of OPTC and biochar was conducted by using thermogravimetric analyser (TGA) PerkinElmer Pyris1. The proximate analysis method was adopted from the application of thermal analysis note of PerkinElmer (Cassel et al., 2012). Briefly, the biomass ( $2.5 \mathrm{mg}$, as received) was loaded into the crucible. The material was then weighed at $25^{\circ} \mathrm{C}$. It was heated to $110^{\circ} \mathrm{C}$ at $10^{\circ} \mathrm{C} \mathrm{min}^{-1}$ with a nitrogen flow rate of $10 \mathrm{ml} \mathrm{min}^{-1}$. The heated material was held at $110^{\circ} \mathrm{C}$ for $10 \mathrm{~min}$ to allow water to evaporate. Then, it was heated from $110^{\circ} \mathrm{C}$ to $950^{\circ} \mathrm{C}$ at $10^{\circ} \mathrm{C} \mathrm{min}^{-1}$ with a nitrogen flow rate of

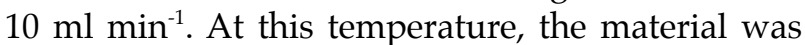
heated for $10 \mathrm{~min}$ to determine the volatile matter content. The sample atmosphere was then switched to air and held for $10 \mathrm{~min}$. The ash content was determined from the remaining residue. An ultimate analysis of OPTC and biochar which provides the percentage of carbon, hydrogen, nitrogen, sulphur and oxygen in the biomass was determined based on ASTM D5373 method by using Thermo Electron Corporation Flash EA 1112 series (CHNS) analyser with autosampler and Eager 300 software (ASTM International, 1993).

To determine the chloride content of OPTC and biochar, chloride was extracted according to the nitric acid extraction procedure (Anon., 2010) followed

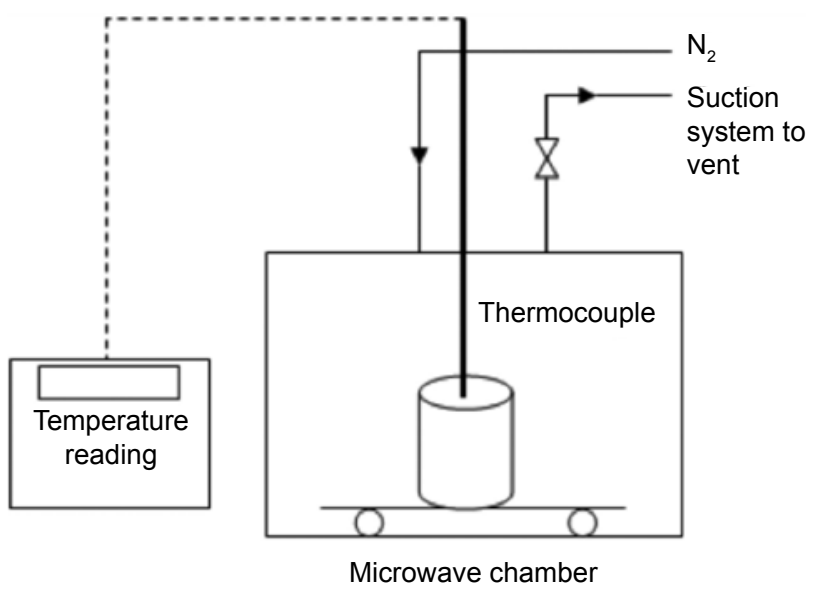

Figure 1. Microwave reactor system. 
by chromatography analysis using a Dionex Ion Chromatography System ICS-1100 with suppressor ASRS-4mm analysis. AAS PerkinElmer AAnalyst 400 Atomic Absorption Spectrophotometer was used to quantify the inorganic species of OPTC and biochar including potassium and sodium. The metal solution was prepared by perchloric-nitric acid digestion procedure (Hseu, 2004). For calorific value of OPTC and biochar, bomb calorimeter (Model: Parr 1341 Plain Jacket Calorimeter) was used based on ASTM D2015 method (ASTM International, 1996).

Analysis of oxide composition in biomass was carried out by Advanced Materials Research Centre, Section 2, SIRIM) using Energy Dispersive Spectrometer (EDS). The sample was dried in an oven for an hour before spreading on a stub and coated with gold. The sample was analysed under a Scanning Electron Microscope (Hitachi S2500) and Oxford Energy Dispersive X-ray Analyser (EDS) at accelerating voltage $20 \mathrm{kV}$. The C-U detection limit was $0.1-1$ at $\%$.

\section{RESULTS AND DISCUSSION}

\section{Heat Rate and Biochar Yield}

Figures $2 a$ and $2 b$ illustrates the average heating rate (standard error $<2 \%$ ) for microwave-assisted carbonisation of $4 \mathrm{~cm}$ and $6 \mathrm{~cm}$ cube sizes. Both of the sizes showed a similar trend that heating rate increased with the increase in the microwave power. This trend was in agreement with Huang et al. (2012) study on rice straw and pennisetum. In comparison to the two OPTC sizes, the result showed that heating rate decreased when larger OPTC was carbonised. The heating rate for carbonisation of the $4 \mathrm{~cm}$ cube was nearly doubled to that of the $6 \mathrm{~cm}$ cube. The result could be explained in terms of dependence of microwave absorption rate to biomass particle size. Previous studies suggested that small biomass particle size has high microwave absorption rate (Barringer et al., 1994; Salema and Ani, 2011). This was due to larger amount of electromagnetic wave being transmitted to the back face thus small biomass size got heated quickly. In contrast, large biomass size has lower absorption rate therefore needs higher microwave power to heat up (Barringer et al., 1994).

As shown in Figures $3 a$ and $3 b$, both of the OPTC sizes showed similar trend in the relationship between biochar yield and temperature. The amount of biochar yield decreased with increasing carbonisation temperature. This trend is similar to the findings of previous carbonisation studies on bagasse (Katyal et al., 2003), woody biomass (Park et al., 2012), rubber seed shell (Ekebafe et al., 2012) and switchgrass (Sadaka et al., 2014).

As for the $4 \mathrm{~cm}$ cube (Figure $3 a$ ), it was noticeable that the biochar yield gradually decreased when the carbonisation temperature increased. The biochar yield from $6 \mathrm{~cm}$ cube also showed a negative relationship with carbonisation temperature. The highest amount of biochar yield was shown at $300^{\circ} \mathrm{C}$ within the same microwave power usage. Unfortunately, the amount of biochar yield at $300^{\circ} \mathrm{C}$ for all selected microwave power $(450 \mathrm{~W}, 600$ $\mathrm{W}$ and $800 \mathrm{~W}$ ) was erratic due to the incomplete carbonisation of OPTC biomass with hot spots remaining at the end of the experiment (Figure $4 a$ ). The hot spots problem was not visually observed at temperature $350^{\circ} \mathrm{C}$ and $400^{\circ} \mathrm{C}$ (Figure $4 b$ ). In Figure $3 b$, for OPTC cube size of $6 \mathrm{~cm}$, an increase of temperature to $400^{\circ} \mathrm{C}$ has decreased the char yield to $5.94 \%, 6.27 \%$ and $7.48 \%$ for the carbonisation by using microwave power of $450 \mathrm{~W}, 600 \mathrm{~W}$ and $800 \mathrm{~W}$, respectively.

The results in Figures $3 a$ and $3 b$ highlighted that biochar yield was negatively correlated to the carbonisation temperature. The stages of carbohydrate degradation during carbonisation

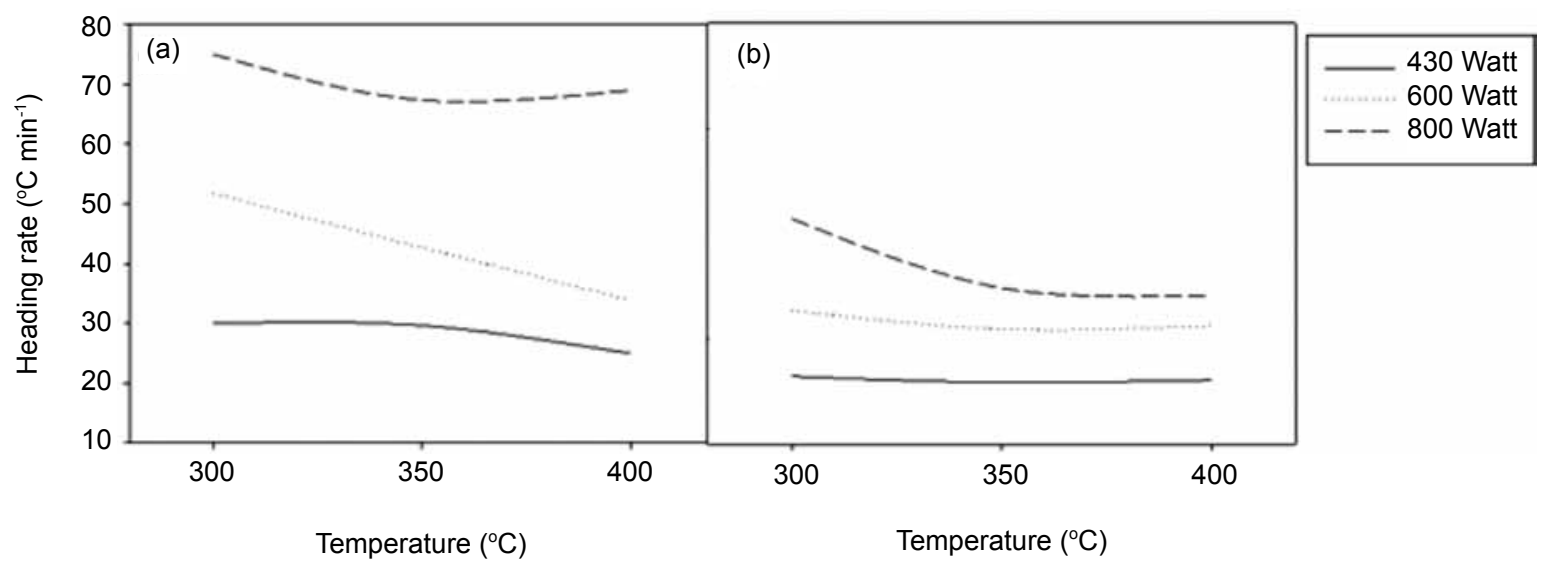

Figure 2. Heat rate for carbonisation of oil palm trunk core (OPTC) sized (a) $4 \mathrm{~cm}$ cube and (b) $6 \mathrm{~cm} \mathrm{cube}$. 


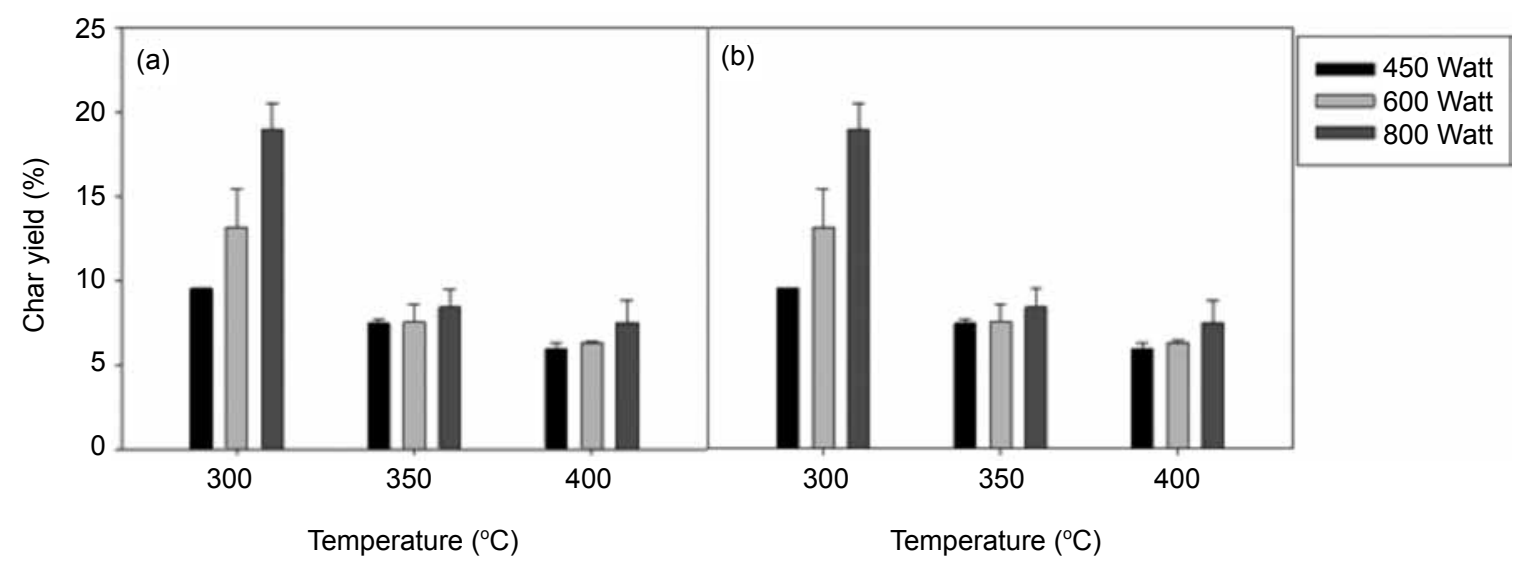

Figure 3. Comparison of biochar yield from oil palm trunk core (OPTC) under various carbonisation temperature and microwave power for (a) 4 cm cube and $(b) 6 \mathrm{~cm}$ cube.

should be noted in order to understand how carbonisation temperature affects biochar yield. During the microwave-assisted carbonisation, moisture and low temperature volatile matter were removed at temperatures below $200^{\circ} \mathrm{C}$. At temperature ranging between $150^{\circ} \mathrm{C}$ to $350^{\circ} \mathrm{C}$, hemicellulose is decomposed (Basu, 2013; Bujang et al., 2013). Cellulose is decomposed at a temperature range of $275^{\circ} \mathrm{C}$ to $350^{\circ} \mathrm{C}$ to produce the major products consisting of char, tar, water, carbon dioxide and carbon monoxide. Furthermore, lignin was decomposed at a temperature range of $250^{\circ} \mathrm{C}$ to $500^{\circ} \mathrm{C}$ and produced biochar (Basu, 2013). Therefore, an increasing temperature would increase the removal of volatile matter and decomposition of hemicellulose, cellulose and lignin and resulted in the decreased yield of the biochar.

Besides the effect of carbonisation temperature, the experiment was performed by using various microwave power in order to study the relationship between microwave power and biochar yield

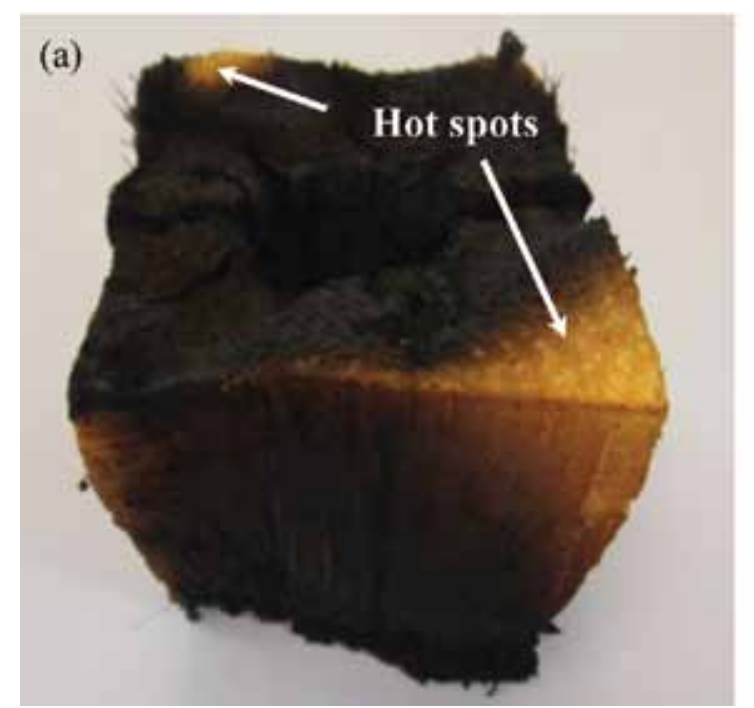

for different sizes of OPTC and carbonisation temperature. For $4 \mathrm{~cm}$ cube OPTC, it was found that a microwave power of $600 \mathrm{~W}$ was the optimum power to be used as this power produced the highest amount of biochar yield at carbonisation temperatures of $350^{\circ} \mathrm{C}$ and $400^{\circ} \mathrm{C}$.

The carbonisation of $4 \mathrm{~cm}$ cube at $600 \mathrm{~W}$, yielded $8.61 \%$ and $8.28 \%$ of biochar for reaction temperature of $350^{\circ} \mathrm{C}$ and $400^{\circ} \mathrm{C}$, respectively. In Figure 3, the biochar yield was positively correlated with microwave power for $6 \mathrm{~cm}$ cube. The microwave power of $450 \mathrm{~W}$ produced the lowest amount of biochar yield; $7.44 \%$ (at temperature $350^{\circ} \mathrm{C}$ ) and $5.94 \%$ at $400^{\circ} \mathrm{C}$ for $6 \mathrm{~cm}$ cube size, respectively. The highest biochar yield was produced with microwave power of $800 \mathrm{~W}$ which gave $8.40 \%$ and $7.48 \%$ of biochar at $350^{\circ} \mathrm{C}$ and $400^{\circ} \mathrm{C}$, respectively.

The trend of increased biochar yield with microwave power was obvious for $6 \mathrm{~cm}$ cube. This could be explained in terms of reliance of microwave penetration depth to biomass particle size. In an

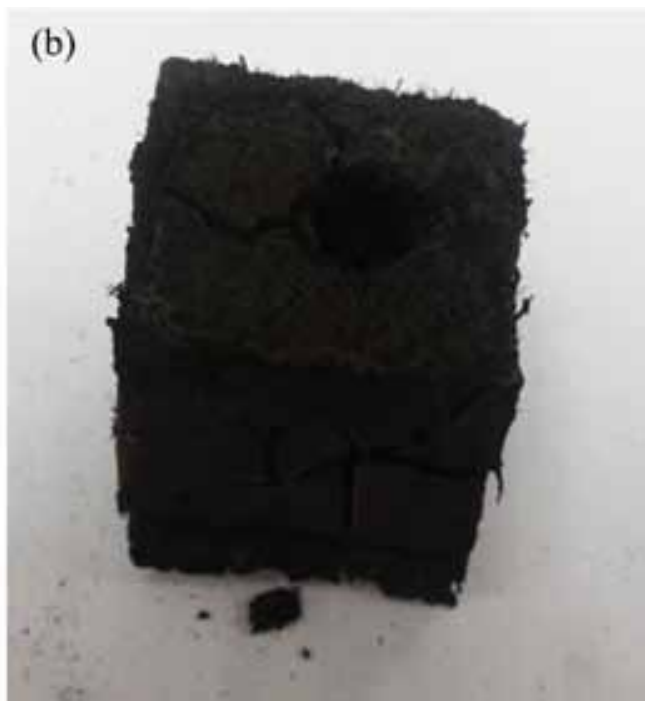

Figure 4. Biochar produced from $6 \mathrm{~cm}$ cube size, power $450 \mathrm{~W}$ at (a) $300^{\circ} \mathrm{C}$ and (b) $400^{\circ} \mathrm{C}$. 
earlier study on oil palm shell biomass, it was found that microwave penetration depth for small particles was higher than large particles (Salema and Ani, 2011). The authors relate this finding to the increase of heat transfer rate in smaller particles compared to larger particles. The trend of heat transfer rate obtained in the present study (Figure 2) agrees well with previous findings. In addition, the biochar yield for $4 \mathrm{~cm}$ cube at $600 \mathrm{~W}, 350^{\circ} \mathrm{C}(8.61 \%)$ was similar to that obtained for $6 \mathrm{~cm}$ cube at $800 \mathrm{~W}, 350^{\circ} \mathrm{C}$ $(8.4 \%)$. This suggests that at similar temperature, larger cube block needs higher microwave power to impose similar heat transfer effect as that achieved by smaller block at lower microwave power.

\section{Proximate and Ultimate Analysis}

Organic species in OPTC and biochars are characterised based on proximate and ultimate analyses which help in determining the energy and ash content. Proximate and ultimate analyses of OPTC and biochars are presented in Table 1. Through carbonisation, the moisture of biochars was reduced to about $80 \%-97 \%$ lower than the moisture in raw OPTC. The reduction in moisture content is advantageous as it provides a longer storage period for the biochar. In this study, the moisture content in most of biochars is less than $10 \%$ (with the exception of S450T350 biochar). According to a guideline published previously (Khan et al., 2009), it could be assumed that the low moisture-biochar products tend to reduce ignition problem and increases the combustion temperature during its application as biofuel. The moisture content of biochar products listed in Table 1 is also comparable to moisture content in Collie coal, a low rank coal.

The volatile matter in biochars was significantly increased (with the exception of F450T400, F600T400 and F800T400 biochars) than those in raw OPTC. Biofuels with high volatile matter content are easier to ignite and their combustion rate are much more rapid than that of raw biomass (Khan et al., 2009). Therefore, the biochars produced in this study will be easy to burn during the biofuel application. As shown in Table 1, the volatile matter of biochar decreased with increasing carbonisation

TABLE 1. PROXIMATE AND ULTIMATE ANALYSIS OF OIL PALM TRUNK CORE (OPTC) AND BIOCHAR

\begin{tabular}{|c|c|c|c|c|c|c|c|c|c|}
\hline \multirow[t]{2}{*}{ Sample } & \multicolumn{4}{|c|}{ Proximate analysis $(\%$, ar $)$} & \multicolumn{5}{|c|}{ Ultimate $(\%$, daf) } \\
\hline & Moisture & VM & FC & Ash & $\mathrm{C}$ & $\mathbf{H}$ & $\mathbf{N}$ & $\mathrm{S}$ & $\mathbf{O}^{*}$ \\
\hline OPTC & 64.30 & 25.70 & 6.43 & 3.57 & 40.26 & 5.88 & 0.00 & 0.00 & 53.86 \\
\hline Collie $^{a}$ & 5.50 & 34.90 & 51.10 & 8.50 & 74.00 & 4.30 & 1.30 & 0.60 & 19.80 \\
\hline F450T300 & 4.94 & 39.57 & 40.13 & 15.37 & 66.65 & 2.02 & 0.00 & 0.00 & 31.33 \\
\hline F450T350 & 5.15 & 28.50 & 49.03 & 17.32 & 68.72 & 1.22 & 0.00 & 0.00 & 30.06 \\
\hline F450T400 & 4.01 & 17.97 & 58.87 & 19.15 & 69.20 & 1.75 & 0.00 & 0.00 & 29.05 \\
\hline F600T300 & 2.78 & 32.11 & 47.72 & 17.39 & 67.29 & 2.46 & 0.00 & 0.00 & 30.25 \\
\hline F600T350 & 1.82 & 29.23 & 50.38 & 18.57 & 69.85 & 1.56 & 0.00 & 0.00 & 28.59 \\
\hline F600T400 & 4.70 & 19.80 & 64.47 & 11.03 & 70.99 & 1.42 & 0.00 & 0.00 & 27.59 \\
\hline F800T300 & 6.16 & 29.80 & 32.26 & 8.94 & 66.61 & 1.15 & 0.00 & 0.00 & 32.24 \\
\hline F800T350 & 3.47 & 38.02 & 43.63 & 14.88 & 67.04 & 1.44 & 0.00 & 0.00 & 31.52 \\
\hline F800T400 & 2.57 & 18.13 & 63.06 & 16.24 & 69.14 & 1.66 & 0.00 & 0.00 & 29.20 \\
\hline S450T300 & 8.59 & 51.63 & 28.28 & 11.50 & 70.89 & 1.04 & 0.00 & 0.00 & 28.07 \\
\hline S450T350 & 12.92 & 33.55 & 47.64 & 5.89 & 73.39 & 1.62 & 0.00 & 0.00 & 24.99 \\
\hline S450T400 & 4.21 & 35.44 & 48.41 & 11.94 & 74.53 & 1.55 & 0.00 & 0.00 & 23.92 \\
\hline S600T300 & 8.61 & 60.24 & 20.06 & 11.09 & 67.43 & 3.24 & 0.00 & 0.00 & 29.33 \\
\hline S600T350 & 3.90 & 43.61 & 43.28 & 9.21 & 69.88 & 0.86 & 0.00 & 0.00 & 29.26 \\
\hline S600T400 & 4.55 & 31.78 & 50.98 & 12.69 & 73.00 & 0.93 & 0.00 & 0.00 & 26.07 \\
\hline S800T300 & 7.58 & 56.87 & 25.45 & 10.10 & 69.25 & 2.68 & 0.00 & 0.00 & 28.07 \\
\hline S800T350 & 6.66 & 32.07 & 48.31 & 12.96 & 70.98 & 1.61 & 0.00 & 0.00 & 27.41 \\
\hline S800T400 & 5.66 & 32.86 & 53.35 & 8.13 & 73.76 & 1.57 & 0.00 & 0.00 & 24.67 \\
\hline
\end{tabular}

Note: ${ }^{a}$ Collie coal data was cited from Abdullah and $\mathrm{Wu}(2009), \mathrm{VM}=$ volatile matter, $\mathrm{FC}=$ fixed carbon, ar $=$ as received, daf $=$ dry ash free, *denotes by difference, FxxxTzzz = biochar prepared from the carbonisation of $4 \mathrm{~cm}$ cube OPTC with microwave power xxx W at temperature $\mathrm{zzz}^{\circ} \mathrm{C}, \mathrm{SxxxTzzz}=$ biochar prepared from the carbonisation of $6 \mathrm{~cm}$ cube OPTC with microwave power xxx W at temperature $\mathrm{zzz}^{\circ} \mathrm{C}$. 
temperature. The volatile matter was removed during the decomposition of hemicellulose, cellulose and lignin (Sadaka et al., 2014). As the volatile matter was removed, the fixed carbon content of the biochars increased and its carbon content also increased, resulting in high energy content.

In comparison, all of the biochars have better fuel quality than raw OPTC as biochars have higherfixed carbon and low moisture content. The highfixed carbon content indicated that biochars have high heating capacity. Raw feedstock size seemed to affect the fixed carbon content of biochar. Under similar reactor conditions, most of the smaller biochar size (produced from $4 \mathrm{~cm}$ cube OPTC) contained higher fixed carbon content than those of the larger biochar size produced from $6 \mathrm{~cm}$ cube OPTC. The biochar F600T400 has the highest fixed carbon value of $64.47 \%$. From the data, the fixed carbon content in biochars also correlates positively with the increment of carbonisation temperature.

In Table 1, the ash content of biochars increased after carbonisation compared to $3.57 \%$ ash in raw OPTC. The highest ash content of biochar was found in F450T400 biochar (19.15\%). Ash is the inorganic residue that contributes to the operational problem. The increase of ash content brings disadvantages in biochar application as biofuel because the ash tends to increase the formation of pollutant and dust, and it also increases the tendency of slagging, fouling and corrosion (Vamvuka and Kakaras, 2011).

Based on the ultimate analysis, the hydrogen content of $5.88 \%$ in OPTC has decreased to the lowest of $0.86 \%$ in biochar S600T350. The hydrogen content of biochar products are also much lower than that of Collie coal $(4.3 \%)$. The carbonisation also decreased the oxygen content from $53.86 \%$ to $24.67 \%$ in OPTC and biochar S800T40, respectively. The loss in hydrogen and oxygen content may be due to dehydration and breaking of the weaker bonds within the biomas structures during carbonisation. The degradation of bonds in biomass led to increased of carbon content in the char product (Capareda, 2013). In terms of carbon content, biochar S450T400 has a similar amount of carbon $(74.5 \%)$ to that of Collie coal. The data proved that microwave assisted-carbonisation conducted in this study has succeeded in converting OPTC biomass into biochars with much improved fuel properties comparable to Collie coal.

Figure 5 illustrates relationship between ratio of hydrogen-to-carbon $(\mathrm{H} / \mathrm{C})$ and oxygen-tocarbon $(\mathrm{O} / \mathrm{C})$ content for OPTC and biochar. The biochars have a very low $\mathrm{H} / \mathrm{C}$ ratio and $\mathrm{O} / \mathrm{C}$ ratio compared to raw OPTC. The $\mathrm{H} / \mathrm{C}$ ratio of biochar decreased because hydrogen was removed through dehydration and dehydrogenation reactions, cleavage and cracking of weak hydrogen bonds within the biochar (Qian et al., 2013). On the other hand, the removal of oxygen through dehydration and decarboxylation caused the decreasing of $\mathrm{O} / \mathrm{C}$ ratio (Basu, 2010). As shown in Figure 5, all of the biochars have better heating properties than the raw OPTC. The $\mathrm{H} / \mathrm{C}$ and $\mathrm{O} / \mathrm{C}$ ratios decreased with increasing carbonisation temperature and produced biochar with higher heating values.

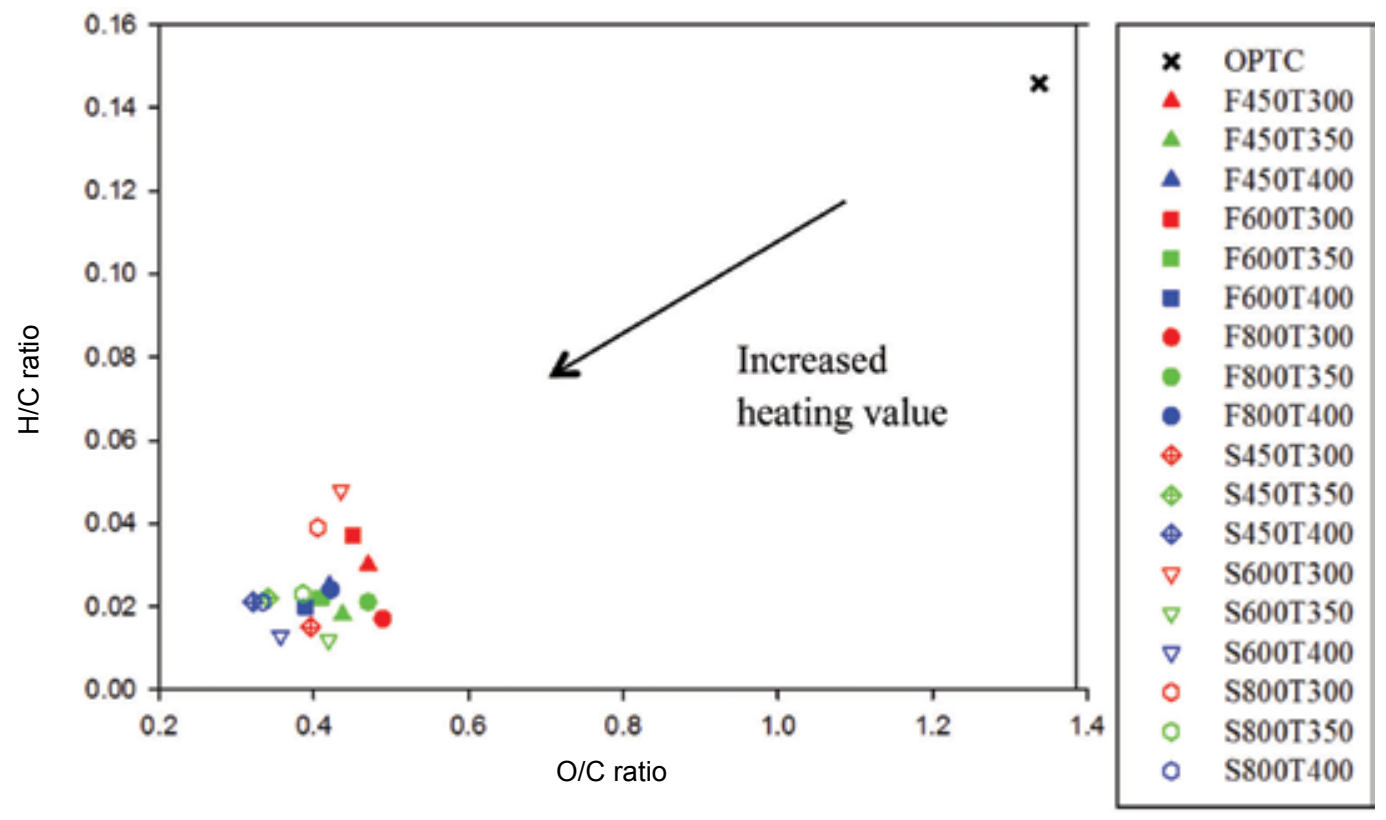

Figure 5. Relationship between ratio of hydrogen-to-carbon $(\mathrm{H} / \mathrm{C})$ and oxygen-to-carbon $(\mathrm{O} / \mathrm{C})$ content for OPTC and biochar. OPTC $=$ oil palm trunk core, FxxxTzzz= biochar prepared from the carbonisation of $4 \mathrm{~cm}$ cube OPTC with microwave power $x x x$ W at temperature $z z z^{\circ} \mathrm{C}$, SxxxTzzz $=$ biochar prepared from the carbonisation of $6 \mathrm{~cm}$ cube OPTC with microwave power $x x x W$ at temperature zzz ${ }^{\circ} \mathrm{C}$. 


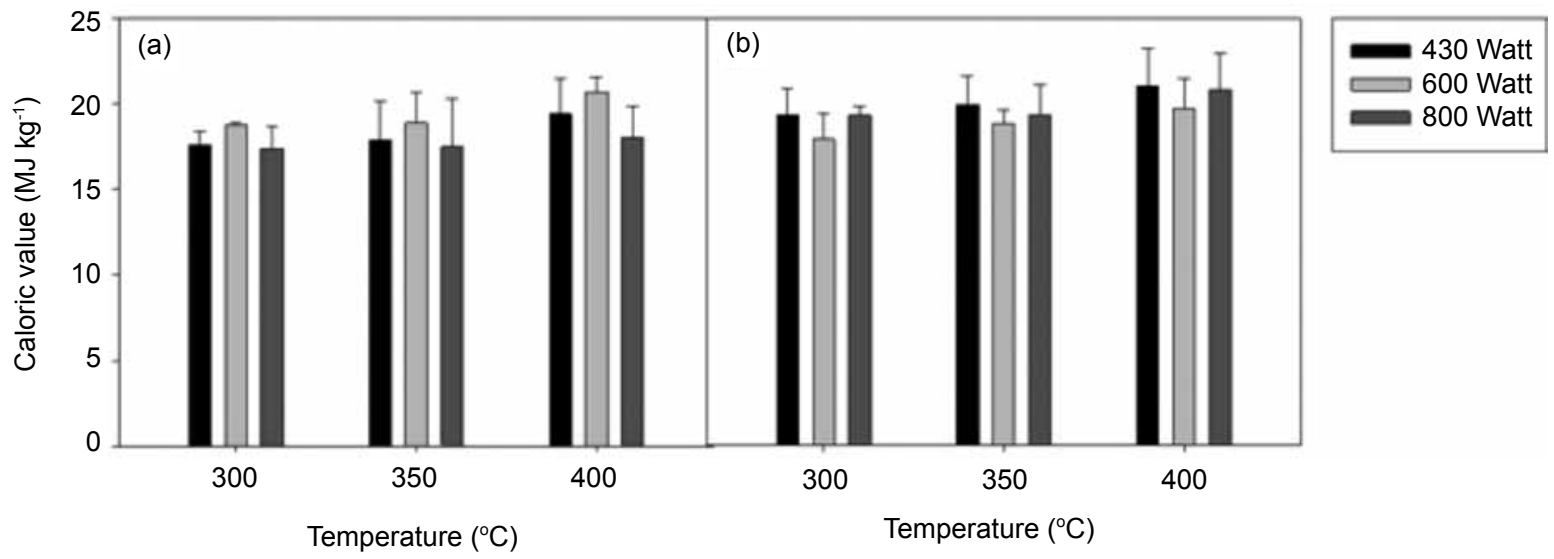

Figure 6. Calorific value of biochars for (a) $4 \mathrm{~cm}$ cube and (b) $6 \mathrm{~cm}$ cube. Note: Calorific value of oil palm trunk core (OPTC) is $4.6 \mathrm{MJ} \mathrm{kg}^{-1}$.

\section{Calorific Value of Biochars}

The energy content of biochars were analysed and the average calorific values are presented in Figure 6. The calorific value of biochar was found to increase when the carbonisation temperature increased. The calorific values in Figure 6 were in agreement with the data in Figure 5 based on Dulong's equation [Equation (2)] (Liu et al., 1996) highlighting the increase of carbon content and decrease of oxygen content after carbonisation process have increased the calorific value of biochar.

Calorific value $=81 \mathrm{C}+342.5(\mathrm{H}-\mathrm{O} / 8)+22.5 \mathrm{~S}-6(9 \mathrm{H}+\mathrm{W})$ Equation (2)

where: $\mathrm{C}=$ weight percentage of carbon;

$\mathrm{H}=$ weight percentage of hydrogen;

$\mathrm{O}=$ weight percentage of oxygen;

$\mathrm{S}=$ weight percentage of sulphur; and

$\mathrm{W}=$ weight percentage of water.

The calorific value of the biochars was benchmarked to the value obtained for raw OPTC $\left[4.6 \mathrm{MJ} \mathrm{kg}^{-1}(\mathrm{ar})\right]$. Through carbonisation, the calorific value was increased to about four times higher than the values obtained for raw OPTC. It is interesting to note that by microwave irradiation carbonisation, the calorific value of biochar has dramatically increased through the short reaction time. Table 2 provides a comparison of calorific value for biochars obtained from OPTC in this study with biochars produced from other sources of oil palm biomass reported in previous studies. From Table 2, the energy values of biochar produced from OPTC cubes in this study are in similar range to those produced from millimetre sized-empty fruit bunch (Salema and Ani, 2012) and centimetre-sized oil palm frond (Rahman et al., 2014).

\section{Inorganic Species as Indicator for Slagging Tendency}

Inorganic species in OPTC and biochars were also characterised because they significantly contribute to the reactor problems such as aerosol emissions, slagging and fouling. Fouling is the accumulation of unwanted materials on the surface of the reactor that causes efficiency of exchanger tubing of the reactor to decrease (Monti et al., 2008). Slagging is the formation of glassy layer on the surface of reactor by the low melting point of deposits (Monti et al., 2008). Alkali index (AI), total alkalis (TA) and molar ratio of $\mathrm{Na}$ and $\mathrm{K}$ to $\mathrm{S}$ and $\mathrm{Cl}$ were used to predict the slagging and fouling tendency of biochars. The index values of biochars were compared with those of raw OPTC and shown in Table 3. In bioenergy

TABLE 2. CALORIFIC VALUE OF BIOCHAR PRODUCED FROM OTHER OIL PALM BIOMASSES

\begin{tabular}{|c|c|c|c|c|}
\hline Source of biochar & Sample size & Type of reactor & $\begin{array}{l}\text { Calorific value } \\
\left.(\mathrm{MJ} \mathrm{kg})^{-1}\right)\end{array}$ & Reference \\
\hline Oil palm trunk core & $\begin{array}{l}\text { Cube sample with } 4 \times 4 \times 4 \mathrm{~cm} \text { and } \\
6 \times 6 \times 6 \mathrm{~cm}\end{array}$ & Microwave & $17.4-21.0$ & In this study \\
\hline Empty fruit bunch & $\begin{array}{l}\text { Pellet with } 4-40 \mathrm{~mm} \text { long and } 7 \mathrm{~mm} \\
\text { diameter }\end{array}$ & Microwave & $20.0-25.0$ & Salema and Ani (2012) \\
\hline Oil palm shell & Particle sized $1.4 \mathrm{~mm}$ & Microwave & $26.0-29.0$ & $\begin{array}{l}\text { Abubakar and Ani } \\
\text { (2013) }\end{array}$ \\
\hline Oil palm fronds & Sample with $6-8 \mathrm{~cm}$ length & Fixed bed reactor & $18.0-19.0$ & Rahman et al. (2014) \\
\hline
\end{tabular}


applications, the guideline limits for both $\mathrm{AI}$ and TA values in biomass are $\mathrm{AI}=0.34 \mathrm{~kg} \mathrm{GJ}^{-1}$ and $\mathrm{TA}=0.4$ (Sommersacher et al., 2012).

From Table 3, all of the biochars showed higher AI and TA values than those obtained from raw OPTC. The biochars' AI and TA values were all way above the guideline limits. This indicates that biochars have high slagging and fouling tendency. It is interesting to note that the index values of 6 $\mathrm{cm}$ cube were lower than $4 \mathrm{~cm}$ cube. For example, biochar F800T400 (produced from $4 \mathrm{~cm}$ cube, at 800 $\mathrm{W}, 400^{\circ} \mathrm{C}$ ) obtained $2.23 \mathrm{~kg} \mathrm{GJ}^{-1}$ for AI which is almost double to $1.38 \mathrm{~kg} \mathrm{GJ}^{-1}$ of biochar S800T400 (from 6 $\mathrm{cm}$ cube, at $800 \mathrm{~W}, 400^{\circ} \mathrm{C}$ ). The TA value decreased from 4.02 to 2.87 for biochar F800T400 and S800T400 when the size of OPTC increased from $4 \mathrm{~cm}$ cube to $6 \mathrm{~cm}$ cube. In addition, the AI and TA of biochar S800T400 (AI: 1.38 and TA: 2.87) were close to that of raw OPTC's indices (AI: 1.30 and TA: 1.13). An increase of microwave power tended to lower both of the index values for the larger OPTC size.

In comparing raw OPTC and biochars, the molar ratio of $\mathrm{Na}$ and $\mathrm{K}$ to $\mathrm{S}$ and $\mathrm{Cl}$ has largely decreased from 155.22 to a value of less than 5.5 after the carbonisation. With a low molar ratio of $\mathrm{Na}$ and $\mathrm{K}$ to $\mathrm{S}$ and $\mathrm{Cl}$, biochars have lower possibility in alkali silicates formation than OPTC. However, the values of biochars are more than 1 , which is still above the threshold value of the guideline indicating that alkali silicates tend to form (Sommersacher et al., 2012).

Other than that, the elements silicon (Si), potassium $(\mathrm{K})$ and calcium $(\mathrm{Ca})$ involved in the reactions lead to slagging problems (Jenkins et al., 1998). The silicon-to-potassium $(\mathrm{Si} / \mathrm{K})$ ratio and calcium-topotassium $(\mathrm{Ca} / \mathrm{K})$ ratio are indicators in evaluating biochars' slagging tendency (Monti et al., 2008). As

TABLE 3. ALKALI INDEX AND TOTAL ALKALIS OF OIL PALM TRUNK CORE (OPTC) AND BIOCHARS

\begin{tabular}{cccc}
\hline Sample & Alkali index, AI $\left(\mathbf{k g ~ G}^{-\mathbf{1}}\right)$ & Total alkalis, $\mathbf{~ A ~}$ & $\frac{\mathbf{N a}+\mathbf{K}}{\mathbf{2 S}+\mathbf{C I}}$ \\
\hline OPTC & 1.30 & 1.13 & 155.22 \\
F450T400 & 3.85 & 7.46 & 3.60 \\
F600T400 & 1.39 & 2.87 & 5.42 \\
F800T400 & 2.23 & 4.02 & 1.04 \\
S450T400 & 1.90 & 3.99 & 2.27 \\
S600T400 & 1.88 & 3.71 & 2.18 \\
S800T400 & 1.38 & 2.87 & 1.83 \\
\hline
\end{tabular}

Note: Fxxxtzzz = biochar prepared from the carbonisation of $4 \mathrm{~cm}$ cube OPTC with microwave power xxx $\mathrm{W}$ at temperature $z z z{ }^{\circ} \mathrm{C}$, SxxxTzzz $=$ biochar prepared from the carbonisation of $6 \mathrm{~cm}$ cube OPTC with microwave power $x x x W$ at temperature $\mathrm{zzz}^{\circ} \mathrm{C}$.

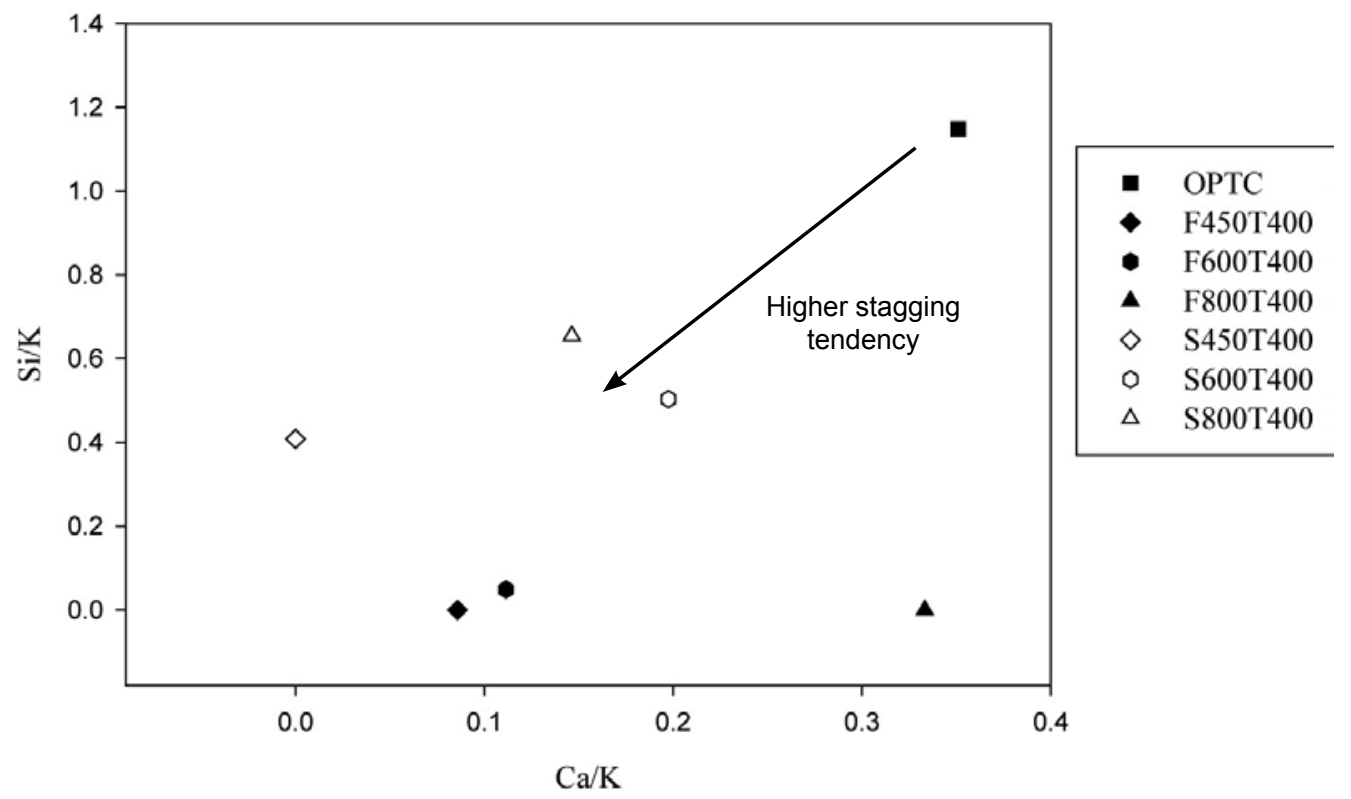

Figure 7. Relationship between silicon-to-potassium (Si/K) and calcium-to-potassium (Ca/K) ratio for OPTC and biochars. OPTC $=$ oil palm trunk core, FxxxTzzz = biochar prepared from the carbonisation of $4 \mathrm{~cm}$ cube OPTC with microwave power $x x x$ W at temperature $z z z^{\circ} \mathrm{C}, S x x x T z z z=b i o c h a r$ prepared from the carbonisation of $6 \mathrm{~cm}$ cube OPTC with microwave power $x x x \mathrm{~W}$ at temperature $z z z^{\circ} \mathrm{C}$. 
shown in Figure 7, biochar of $4 \mathrm{~cm}$ cube size showed lower $\mathrm{Si} / \mathrm{K}$ and $\mathrm{Ca} / \mathrm{K}$ ratios than the ratios obtained from biochar of $6 \mathrm{~cm}$ cube size. This implicates that biochar of $4 \mathrm{~cm}$ cube size is at higher risk to cause slagging and fouling problem. This is because an increasing $\mathrm{K}$ content decreases the ash melting point that causes the slagging and formation of hard deposit at higher temperature (Omar et al., 2011). Therefore, biochar with lower $\mathrm{Si} / \mathrm{k}$ and $\mathrm{Ca} / \mathrm{K}$ ratios shows a high propensity of slagging during combustion (Abdullah et al., 2010).

\section{CONCLUSION}

In the study of microwave-assisted carbonisation of OPTC, it was found that the increase in carbonisation temperature had decreased the biochar yield. The carbonisation process had produced biochar with better fuel quality compared to the raw biomass. The biochar derived from OPTC has lower moisture content, but with higher fixed carbon content and volatile matter. The energy value of biochars was increased to about four times higher than the energy value of raw OPTC and the values range were similar to biochars from other sources of oil palm biomass. The propensity of slagging and fouling of biochars produced from $6 \mathrm{~cm}$ cube was lower than that of $4 \mathrm{~cm}$ cube biochar. This is because biochars of $6 \mathrm{~cm}$ cube have lower AI, TA and molar ratio of $\mathrm{Na}$ and $\mathrm{K}$ to $\mathrm{S}$ and $\mathrm{Cl}$ while higher $\mathrm{Si} / \mathrm{K}$ and $\mathrm{Ca} / \mathrm{K}$ ratios.

\section{ACKNOWLEDGEMENT}

The authors would like to acknowledge the Ministry of Higher Education, Malaysia for funding this research through FRGS Code 2012-0001-104-02.

\section{REFERENCES}

ABDULLAH, H and WU, H (2009). Biochar as a fuel: 1. properties and grindability of biochars produced from the pyrolysis of mallee wood under slowheating conditions. Energy Fuels, 23(8): 4174 - 4181.

ABDULLAH, H; MEDIASWANTI, K A and WU, H (2010). Biochar as a fuel: 2. significant differences in fuel quality and ash properties of biochars from various biomass components of mallee trees. Energy Fuels, 24(3): 1972 - 1979.

ABUBAKAR, Z and ANI, F N (2013). Microwaveassisted pyrolysis of oil palm shell biomass. J. Mekanikal, 36: 19 - 30.

AMOUZGAR, P; KHALIL, H PS A; SALAMATINIA, B; ABDULLAH, A Z and ISSAM, A M (2010). Optimization of bioresource material from oil palm trunk core drying using microwave radiation; a response surface methodology application. Bioresource Technology, 101(21): 8396-8401.

ANON. (2010). Waite analytical services (WAS). University of Adelaide.

ASTM INTERNATIONAL (1996). ASTM D2015: Standard Test Method for Gross Calorific Value of Solid Fuel by the Adiabatic Bomb Calorimeter.

ASTM INTERNATIONAL (1993). ASTM D5373-08 Standard Test Methods for Instrumental Determination of Carbon, Hydrogen and Nitrogen in Laboratory Samples of Coal.

BARRINGER, S A; DAVIES E A; GORDON J; AYAPPA, K G and DAVIS H T (1994). Effect of sample size on the microwave heating rate: oil vs. water. AIChE J., 40(9): 1433-1439.

BASU, P (2010). Biomass Gasification and Pyrolysis: Practical Design and Theory. Elsevier, Oxford, United Kingdom.

BASU, P (2013). Biomass Gasification, Pyrolysis and Torrefaction: Practical Design and Theory. $2^{\text {nd }}$ edn. Elsevier, London.

BUJANG, N; RODHI, M N M; MUSA, M; SUBARI, F; IDRIS, N; MAKHTAR, N S M and HAKIM, K H K (2013). Effect of dilute sulfuric acid hydrolysis of coconut dregs on chemical and thermal properties. Procedia Engineering, 68: 372-378.

CAPAREDA, S (2013). Introduction to Biomass Energy Conversions. CRC Press, USA.

CASSEL, B; MENARD, K and EARNEST, C (2012). Proximate Analysis of Coal and Coke using the STA 8000 Simultaneous Thermal Analyzer. PerkinElmer, USA.

DUNGANI, R; JAWAID, M; ABDUL KHALIL, H P S; JASNI; APRILIA, S; HAKEEM, K R; HARTATI, $S$ and ISLAM, M N (2013). A review on quality enhancement of oil palm trunk waste by resin impregnation: future materials. BioResources, 8(2): 3136 - 3156.

EKEBAFE, L O; IMANAH, J E and OKIEIMEN, F E (2012). Effect of carbonisation on the processing characteristics of rubber seed shell. Arabian J. Chemistry.

EOM, I-Y; YU, J-H; JUNG, C-D and HONG, K-S (2015). Efficient ethanol production from dried oil palm trunk treated by hydrothermolysis and subsequent enzymatic hydrolysis. Biotechnology for Biofuels, 8(1): 83. 
HAQUE, K E (1999). Microwave energy for mineral treatment processes - a brief review. International J. Mineral Processing, 57(1): 1-24.

HSEU, Z Y (2004). Evaluating heavy metal contents in nine composts using four digestion methods. Bioresource Technology, 95(1): 53 - 59.

HUANG, Y F; CHEN, W R; CHIUEH, P T; KUAN, W H and LO, S L (2012) Microwave torrefaction of rice straw and pennisetum. Bioresource Technology, 123: $1-7$.

JAHIRUL, M I; RASUL, M G; CHOWDHRY, A A and ASHWATH, N (2012). Biofuels production through biomass pyrolysis - a technological review. Energies, 5(12): 4952 - 5001.

JENKINS, B M; BAXTER, L L; MILES JR T R and MILES, T R (1998). Combustion properties of biomass. Fuel Processing Technology, 54(1-3): 17 - 46.

KATYAL, S; THAMBIMUTHU, $\mathrm{K}$ and VALIX, $\mathrm{M}$ (2003). Carbonisation of bagasse in a fixed bed reactor: influence of process variables on char yield and characteristics. Renewable Energy, 28(5): 713 725 .

KHAN, A A; DE JONG, W; JANSENS, P J and SPLIETHOFF, H (2009). Biomass combustion in fluidized bed boilers: potential problems and remedies. Fuel Processing Technology, 90(1): 21- 50.

LEE, S H; CHEN, L W; SAN, H P; PENG, T L; JINN, C M; WEN, C E and LING, C K (2015). Properties of particleboard with oil palm trunk as core layer in comparison to three-layer rubberwood particleboard. J. Oil Palm Res. Vol. 27(1): 67 - 74.

LIU, J-I; PAODE, R D and HOLSEN, T M (1996). Modeling the energy content of municipal solid waste using multiple regression analysis. J. Air $\mathcal{E}$ Waste Management Association, 46(7): 650 - 656.

LOH, Y; TAHIR, P and YEOH, B (2011). Density distribution of oil palm stem veneer and its influence on plywood mechanical properties. J. Applied Sciences, 11(5): 824 - 831.

MENÉNDEZ, J A; INGUANZO, $\mathrm{M}$ and PIS, J J (2002). Microwave-induced pyrolysis of sewage sludge. Water Research, 36(13): 3261 - 3264.

MENÉNDEZ, J A; DOMÍNGUEZ, A; INGUANZO, $M$ and PIS, J J (2005). Microwave-induced drying, pyrolysis and gasification (MWDPG) of sewage sludge: vitrification of the solid residue. J. Analytical and Applied Pyrolysis, 74(1-2): 406 - 412.
MENÉNDEZ, J A; ARENILLAS, A; FIDALGO, B; FERNÁNDEZ, Y; ZUBIZARRETA, L; CALVO, E G and BERMÚDEZ, J M (2010). Microwave heating processes involving carbon materials. Fuel Processing Technology, 91(1): 1 - 8 .

MIURA, M; KAGA, H; SAKURAI, A; KAKUCHI, $\mathrm{T}$ and TAKAHASHI, K (2004). Rapid pyrolysis of wood block by microwave heating. J. Analytical Applied Pyrolysis, 71: 187 - 199.

MONTI, A; VIRGILIO, N D I and VENTURI, G (2008). Mineral composition and ash content of six major energy crops. Biomass and Bioenergy, 32(3): 216 $-223$.

OMAR, R; IDRIS, A; YUNUS, R and KHALID, K (2010). Microwave absorber addition in microwave pyrolysis of oil palm empty fruit bunch. Proc. of the Venice 2010 Third International Symposium on Energy from Biomass Waste.

OMAR, R; IDRIS, A; YUNUS, R; KHALID, K and ISMA, M I A (2011). Characterization of empty fruit bunch for microwave-assisted pyrolysis. Fuel, 90(4): 1536-1544.

PARK, S-W; JANG, C-H; BAEK, K-R and YANG, $\mathrm{J}-\mathrm{K}$ (2012). Torrefaction and low-temperature carbonisation of woody biomass: evaluation of fuel characteristics of the products. Energy, 45(1): 676685.

PELAEZ-SAMANIEGO, M; GARCIA-PEREZ, M; CORTEZ, L; ROSILLO-CALLE, F and MESA, J (2008). Improvements of Brazilian carbonisation industry as part of the creation of a global biomass economy. Renewable and Sustainable Energy Reviews, 12(4): 1063-1086.

QIAN, K; KUMAR, A; PATIL, K; BELLMER, D; WANG, D; YUAN, W and HUHNKE, R L (2013). Effects of biomass feedstocks and gasification conditions on the physiochemical properties of char. Energies, 6(8): 3972 - 3986.

RAHMAN, A A; ABDULLAH, N and SULAIMAN, F (2014). Temperature effect on the characterization of pyrolysis products from oil palm fronds. Advances in Energy Engineering, 2: 14-21.

ROBINSON, J P; KINGMAN, S W; BARRANCO, $\mathrm{R}$ and SNAPE, C E (2010). Microwave pyrolysis of wood pellets. Industrial and Engineering Chemistry Research, 49(2): 459-463. 
SADAKA, S; SHARARA, M A; ASHWORTH, A; KEYSER, P; ALLEN, F and WRIGHT, A (2014). Characterization of biochar from switchgrass carbonisation. Energies, 7(2): 548 - 567.

SALEMA, A A and ANI, F N (2011). Heating characteristics of biomass and carbonaceous materials under microwave radiation. Proc. of the IEEE First Conference on Clean Energy and Technology (CET).

SALEMA, A A and ANI, F N (2012). Pyrolysis of oil palm empty fruit bunch biomass pellets using multimode microwave irradiation. Bioresource Technology, 125: 102 - 107.

SOMMERSACHER, P; BRUNNER, $\mathrm{T}$ and OBERNBERGER, I (2012). Fuel indexes: a novel method for the evaluation of relevant combustion properties of new biomass fuels. Energy Fuels, 26(1): $380-390$.

SZYMONA, K; CICHY, A; BORYSIUK, P; PAIK, S H and MAMINSKI, M (2011). Selected physical properties of furfurylated oil palm wood (Elaeis guineensis Jacq.). Annals of Warsaw University of Life Sciences - SGGW, Forestry and Wood Technology, (76): $129-133$.
TRUMMER, D R (2004). Biomass-fired CHP in palm oil mill. Report of the Malaysian-Danish Environmental Cooperation Programme Renewable Energy and Energy Efficiency Component.

VAMVUKA, D and KAKARAS, E (2011). Ash properties and environmental impact of various biomass and coal fuels and their blends. Fuel Processing Technology, 92(3): 570 - 581.

WAN ASMA, I; MAHANIM, S; ZULKAFLI, H; OTMAN, S and MORI, Y (2010). Malaysian oil palm biomass. Proc. of the FRIM Regional Workshop on UNEP/DTIE/IETC. 2-5 March 2010, Osaka, Japan.

WUN, S; ABDULLAH, H; YUSOF, N and ABBAS, Z (2015). Dielectric properties of oil palm trunk core. J. Clean Energy Technologies, 3(6): 422 - 427.

YOKOYAMA, S and MATSUMURA, Y (2008). The Asian Biomass Handbook: A Guide for Biomass Production and Utilization. The Japan Institute of Energy, Japan.

ZHAO; X; SONG, Z; LIU, H; LI, Z; LI, L and MA, C (2010). Microwave pyrolysis of corn stalk bale: a promising method for direct utilization of largesized biomass and syngas production. J. Analytical and Applied Pyrolysis, 89(1): 87 - 94. 